\title{
Fluorescein Sodium Injection
}

National Cancer Institute

\section{Source}

National Cancer Institute. Fluorescein Sodium Injection. NCI Thesaurus. Code C82405.

An injectable form of the sodium salt of the fluorophore fluorescein. Fluorescein

responds to electromagnetic radiation between the waveleng ths of $465-490 \mathrm{~nm}$ and

fluoresces, emitting light at wavelengths of 520-530 nm that can be detected visually. 